\title{
Cooking and Processing Fish in Antiquity: Questions of Taste and Texture
}

\author{
John Wilkins ${ }^{1} \mathbb{D}$ \\ Published online: 15 November 2018 \\ (c) The Author(s) 2018
}

\begin{abstract}
Scholars have sometimes given the impression that the consumption of fish in the ancient world was most importantly an obsession of the wealthy and corrupt. The politics of fisheating however is only one small part of the interaction of the Greeks and Romans with fish. The written record shows the widest engagement with fish, their variety and names, along with the cooking, preparation and processing of them. My paper shows that fish are embedded in the cooking codes of the Greeks relating to sacrifice and medicine, and that while fish are wild animals living in an element hostile to human beings, they may also be assimilated into a healthy human body because of their similarity to us. At all times taste is a crucial factor, producing both the perfectly cooked meal and the best state of health in the body - the balancing of the humours.
\end{abstract}

Keywords Greek $\cdot$ Food $\cdot$ Fish $\cdot$ Biology $\cdot$ Nutrition

Much discussion of the preservation and cooking of fish in the ancient world draws on approaches and methods developed in the modern world. This chapter considers the topic from an ancient perspective, as far as we can discern what that is, based on ancient texts. Some argue that the comedies of ancient Athens reveal little about fish consumption (Gallant 1984), others that eating fish was a luxurious activity reserved for the wealthy (Davidson 1997). I shall challenge these propositions: they contain an element of the truth, but do not do justice to the ancient evidence.

All, I think, will agree that the sea was ambiguous in ancient thought: bountiful, but also threatening to life; rich in opportunity but unpredictable and dangerous; part of the wildness of nature along with mountains and uncultivated land beyond fields and cities. Here I review what the Greeks and Romans wrote and thought about eating fish, drawing on the Greeks' extraordinary commitment to three areas of activity: cooking in a broad sense; writing texts; and commenting on fish. This material may be placed beside archaeological and scientific considerations about ancient fish processing to form a composite picture of

John Wilkins

j.m.wilkins@exeter.ac.uk

1 University of Exeter, Exeter, UK 
how fish was prepared and eaten in antiquity. I will concentrate on material from the fifth century BC to about 200 AD, by which time Greek and Roman thought had interacted for centuries.

\section{Cooking and Cooking Codes}

Fishing exists on the margins of culture, which depends on working with or modifying nature to provide food and a sustainable environment: culture, though threatened by nature, can live with it through practices of farming and religion with aid from the gods who control nature and may alleviate famine, disease and death. A key element of culture is fire, identified by the Greeks in the myth of Prometheus, who brought smelting, technology and cooking (pepsis) to ease human vulnerability to nature. Cooking was imagined in two respects in particular, the cooking of an animal in sacrifice and the cooking or digestion of food in the body of humans and other animals.

In sacrifice ('religious' cooking), a domesticated animal was sacrificed in the presence of the worshippers, its blood collected and thrown over the altar; it was flayed, butchered, cooked, distributed in equal portions, and eaten. The cooking skills were deployed to express the power of the immortal gods, who got the bone marrow, and the mortality of the human worshippers who eat the meat and entrails. ${ }^{1}$ This is how Greeks and Romans expressed their Greek or Roman identity. The men and women of Athens or Corinth might sacrifice a bull to the city's god and thereby assert their allegiance and belonging to that community. Fish do not really belong to this eating code-though there are exceptions in the literary and epigraphic record ${ }^{2}$ - and are bought in the market and eaten at private rather than civic gatherings. Because they were not normally linked with civic religion, they had a lesser status in the ancient city. Their value lay essentially in their protein contribution to the diet-supplementing grains and pulses — and in expressing status: rich people enjoyed rarer fish within their luxury diet. Fish are marginal at best in the sacrificial code.

In medicine, however ('biological' cooking), the picture is very different. Here, related cooking skills were used to convert wild food into digestible food as Galen sets out in $O n$ the Properties of Foodstuffs. He considers staple grains first, then meat and fish. In this code a pig has the same role to play as a sea-bass. Digestion is seen as the 'cooking' of food, which the heat of the body transforms into blood. In the early Hippocratic text $O n$ Ancient Medicine cooking is seen as the origin of medicine; this cooking lies behind the incorporation of tastes into the theory of the humours. Cooking is at the heart of medicine and brings the wild into manageable culture. (As we shall see, both biology and cookery books, first seen in the fourth century BC, derive from these medical texts.) The author explains:

For human beings endured much terrible suffering because of their strong and brutish regimen, consuming foods that were raw, unblended, and possessing great powers ... falling into severe pains and diseases followed by a speedy death. ... These people sought for nourishment suited to their constitution and discovered that which we eat today. (3, trans. Schiefsky)

\footnotetext{
${ }^{1}$ Detienne and Vernant (1979).

${ }^{2}$ Purcell (1995).
} 
From wheat, by moistening, winnowing, grinding, sifting, kneading and baking it they made bread, and from barley they made barley cake. And performing many other operations to prepare this nourishment, they boiled and baked and mixed and blended the strong and unblended things with the weaker, molding everything to the constitution and power of the human being. (3, trans. Schiefsky)

This is how to maintain health and alleviate disease: the cooking of food has made possible sustainable digestion and health in human beings. A little later, the human being is revealed to be composed of vital juices - the later humours-which have particular flavours:

For there is in the human being salty and bitter and sweet and acid and astringent and insipid and myriad other things having powers of all kinds in quantity and strength. These when mixed and blended with one another are neither manifest not cause the human being pain; but when one of them separates off and comes to be on its own, then it is both manifest and causes pain (14.4, trans. Schiefsky)

Each food that the human being consumes also has taste qualities, which must be matched up with the individual to produce a balanced blend in the body (Hippocrates, Regimen 2.39):

the power of each food and drink must be identified according to their nature and their preparation as follows. The people who have undertaken to speak in general about sweet foods or fatty foods or salty foods or any power of such foods do not identify them correctly. For sweet things do not all have the same power as each other, nor do fatty foods or any other such foods. For many sweet foods are laxative, but some are constipating; some dry the body, others moisten it. And so it is with all the others.

Sacrifice and medicine may not be the first things that come to the mind in fish studies, but they have two key features: they focus on the terrible power of the natural world, and on the human animal and its mortality. They are ways of regulating the power and rawness of the natural world in order to survive. This is how the Greeks, and Romans too thought about cooking, how the practical skills of preparation, cooking and serving food worked both in the kitchen and in the wider world.

I come now to fish and the sea. Fish are wild animals (a little fish farming is attested). Davidson 1997 argues - partly correctly — that, when brought to the city, they belong to the commercial world of buying and selling, and are linked with pleasure and luxury, with fancy cooking and cookery books, far from the regulated world of domesticated animals eaten as sacrificial meat.

I want to suggest that a more useful approach follows Purcell 1995, on the paradoxes of seafood. Seafood is tasty and nutritious, but supplies are unpredictable, between glut and plenty. Fishermen may be lucky or unlucky. Fishing lacked the stability which farming was thought to provide (though periodically did not). But when the fish were brought from the wildness of the sea into the culture of the city, then eating codes could be brought into play. Taste and pleasure may be achieved in the preparation and cooking of fish; and taste may help the digestion of food in the human body, the human being eating and absorbing fish into him or herself.

In the main Hippocratic treatise on food, the author discusses quadrupeds such as cattle and foxes, birds, fish, and then wild and tame animals. Wild animals are no less a part of the diet than domesticated (Regimen 2.48.1-3): 
Of the fish, the driest are these: scorpios, dragon-fish, kallionumos, kokkux, glaukos, perch, thrissa. Light are nearly all the rock fish, such as the kikle, the phukis, the goby, the elephitis. Such fish are lighter than those that travel far; and insofar as they lead a more tranquil life, they have a flesh that is tender and light...

Salt fish reduces and dries. Fat ones pass through nicely. The driest salt fish are the deep-sea ones, then the river ones, while the moistest are the marsh ones. Of the salted fish, those that were driest as fish are driest when salted.

Hippocratic fish are classified by name, by habitat, by distance swum, by texture. They are classified medically, biologically and by preparation. Many species names are mentioned, along with groupings such as rock-fish. Aristotle's biology develops this, closely observing animals, particularly fish that were brought to his attention; his divisions of classification include the human animal in the same classes as all other animals and fish.

The multiple species of fish also feature in literature, both technical and non-technical, demonstrating extensive engagement with fish and inevitably creating difficulty in matching ancient names to species as now classified. This is best seen in the work of Thompson (1947): principally a biologist, he translated Aristotle and collected Greek names for birds and fish to publish in his celebrated glossaries of birds and fish. He observes that often the ancient name cannot be matched with a modern species, and some ancient observations cannot be confirmed. Many of his identifications have been challenged. Nevertheless the amount of information he collects is extraordinary. A small example (137-139):

'The Gobies are numerous but of little worth, seldom eaten except in the Mediterranean, and there only by the poor; Moreau counts seventeen, and Carus about thirty Mediterranean species.'

'Frequent in Aristotle. The pyloric caeca are said to be numerous in kobios and galeos (H.A. 508b17), but these fishes are remote from one another and the statement is equally untrue of both.'

Sources he cites are: (zoology) Aristotle, Plutarch, Pliny, Dorion, Oppian, Ovid, Theophrastus, and Epicharmus; (food) Antiphanes, Hicesius, Diphilus, and Galen. The doctors, biologists and literary writers have incorporated the wild animals of the sea into the city and classified them for the purposes of human use and knowledge. Sometimes the human use is to eat the fish, but often there is a broader purpose. Take the example of a comedy written by Epicharmus in Sicily early in the fifth century:

[he/she] brought in shellfish of every kind, limpets, aspedoi, krabyzoi, kikibaloi, seasquirts, scallops, balanoi, murex, oysters closed up (to prise them open is difficult, to eat them up easy), mussels, anaritai, whelks and skiphydria... (Epicharmus fr. 42 Kaibel)

Not all these shell-fish are identifiable; some reference is made to eating the oysters. But the range of fish names seem to be the point of the reference. The play is The Marriage of Hebe: the gods seem to attend the wedding in the company of many kinds of fish, which express the wealth of the occasion. The audience was treated to a wide fish vocabulary, which we will shortly find repeated in Athenian comedy.

Why was the theatrical audience of Syracuse interested in long lists of fish names? In early Greek literature, in Homer and Hesiod, the world of fish is remote from human concerns, undesirable, and wild. This changes in later centuries, starting possibly with Epicharmus. Fishermen continued to be rather marginal figures in literature, as in Plautus' play 
The Rope, which shows a young man trying to rescue his girl-friend from a sex trafficker. The kidnapper's boat is shipwrecked on the shore of Cyrene, where the fishermen operate. Though poor, of low status and living a precarious life, they help to prove the girl's identity and advance the love story. They risk the storms that sank the kidnapper's boat; their income is precarious, depending on the many variabilities of fish supplies in the Mediterranean. The sea is capricious: no fish or fish in abundance. Money comes from the fish once taken to market, but that is money for merchants and processors rather than for the fishermen.

There are two strands of engagement with fish, linking into our cooking codes. The fish merchants take over from the fishermen and sell fish to consumers and cooks, through the commercial markets and apart from sacrificial regulation, while the doctors, biologists and literary writers take on the names, varieties and characteristics of fish. The two codes come together to some extent in their recipes for luxurious fish and fish for health, as we shall see. But for the moment, let us say that the doctors and the biologists have watched and spoken to fishermen and incorporated their knowledge and expertise into the knowledge of the city. Aristotle and his researchers spoke to the fishermen of Lesbos about certain species; the Hippocratic doctors similarly had learnt about the habitats and lives of fish. I say that medicine preceded biology only insofar as the Hippocratic texts I quoted predate Aristotle, who in his turn may have developed his interest in biology from his father who was a doctor.

The Hippocratic classifications are based on social practice-the foods that are eaten most often-within the theoretical structure of cooking wild juices into good humour for the body. The author is most interested in softness, dryness and the habitat of fish. Galen, as we shall see, retains habitat with more on cooking. This is how doctors bring fish into the human body and the human world, where the best fish will produce good blood and prove to be very beneficial to the human animal.

\section{Comedy}

I return to the large comic engagement with fish that we have already seen in Epicharmus. Comedy is a strikingly popular medium with large civic engagement. An audience of thousands, not the few readers of a medical treatise. Athenian comedy has lists of fish too, and even a play with a chorus of fish-Archippus' Fishes. Additionally, comedy focuses on the market place, where the ordinary people, represented by the comic characters, buy their food, exchange news and spend their time. It is a popular space, inhabited by the comic demos. Normally in comedies, sacrifice and such regulation remains in the background, validating the proper order when needed. The market is the focus, with a big interest in people who stand out, as being too self-interested, too mercenary, too greedy. The stock character of the hungry man develops from this commercial arena, as does the comic cook who will cook a luxurious lunch based on fish. In the market place people can see if someone is able to buy more expensive fish (Aristophanes, Frogs) than the sprats and anchovies (Acharnians 665-675) available to the general comic population. Fish plays a political role in these plays, with politicians getting the best fish, and fishmongers cheating their customers.

In the Athenian comic theatre, there are many cases of fish being bought by the greedy rich, and by the honest poor, depending upon cost and species. They are used as social markers, often for the rich and aspiring rich, and it is these that Davidson has picked up. People who have profited at public expense, unfairly. Many passages seem to be a mixture 
of fish cooking on a grand scale with much interest in varieties of fish and varieties of cooking. A classic example comes from the fourth century poet Antiphanes:

A: So, then, as for the glaukidion, I'm ordering you to stew it in brine, like the other times.

B: What about the little sea-bass?

A: Roast it whole. B: The dogfish? A: Stew it in a sauce. B: The eel? A: Salt, marjoram and water. B: The conger eel? A: Ditto. B: The skate? A: Green herbs.

B: There's also a tuna steak. A: Roast it.

(trans Olson)

What is the point of this and dozens of passages like it? Do they reflect a development in luxurious eating in the fourth century $\mathrm{BC}$, for which the wealthy increasingly hired fancy cooks? Possibly. But why were comic audiences so interested in all the detail if most of them could not possibly eat in this way? I think these passages with fish-cooking (and some meat cooking as well) take on a life of their own; some of them reflect what is imagined to be upper class and wealthy dining (to be contrasted with what the hard working citizens can afford), but many revel in the myriad possibilities of fish in species, texture (head-meat, tail-meat), and cooking method, expanding the simple pleasure of a long list that we saw in Epicharmus. These details may be unhelpful to the economic historianGallant (1984)—but they are what audiences wanted to hear. Trade statistics belong to our world, not antiquity.

\section{Taste}

I will discuss taste in two parts, taste and pleasure, following a cookery book; and taste and health, following the medical author Galen. Plato's contrast in Gorgias between the doctor who is useful and the cook who merely flatters the taste buds was influential, but has also misled: the doctors were concerned with taste and with texture too, and the quality of 'cooking' was a major concern for them. Fish will give good blood, good humour, as well as taste nice when cooked by the chef. Through taste, then, we can resume the two cooking codes of cooking fish for pleasure outside the regulations of sacrifice and cooking fish for medical benefit.

\section{Taste and Pleasure}

Archestratus of Gela wrote his epic poem in around 360 BC. It concerns fish, its desirability and cost-in the market, not hard-won by fisherman. Athenaeus of Naucratis preserves the poem, in some ways against his better judgement. As a text, it is an outlier: parodic, so derivative; attested in some philosophical and literary works but not widely known; Europe's oldest cookery book, written for an elite, male audience for sympotic recitation in private, in contrast to festival celebrations of Homer and drama (Olson and Sens 2000; Wilkins and Hill 2011). Archestratus affirms what Plato and Xenophon fear of the dangers of luxury in the fourth century BC. He revels in fish-eating, pleasure and desire. At the same time, the poem reflects everything that was important about fish in Greek culture. It puts the flesh back on the bones that are excavated on the archaeological sites of the Aegean and wider Greek world. 
One striking feature is his audience. He tells wealthy men to travel the Mediterranean in search of the best fish. They are to buy it themselves and not worry about the cost; to take account of the seasonality and quality, and then prepare it as directed. Archestratus' rich man is imagined to be both buyer and cook-functions that the rich delegated in practice. Archestratus' Mediterranean is wide and no dangerous barrier: it is bountiful. His diner travels, and so too of course do the fish. However, he is interested in cheaper, shoaling fish-tuna, mackerel, even whitebait-as well as expensive singletons; he is interested too in pickled fish in amphorae.

For the sargos, which belongs to the Sparidae, Archestratus advises (fragment 37):

And when, as Orion is setting in the sky,

The mother of the wine-producing grape cluster begins to shed her hair,

Then get a roasted sargos, sprinkled with cheese,

Nice and big, warm and pierced with pungent vinegar;

For it is naturally hard. I urge you to remember

And treat every tough fish in this same fashion.

But as for that which is good and naturally soft and rich-fleshed,

Treat it by sprinkling it with fine-ground salt only and basting it with olive oil;

For it contains the height of pleasure (terpsis) within itself. (trans. Olson \& Sens)

As we saw earlier, texture is key. The sargos is hard and tough: it needs cheese to soften and enrich, while a naturally soft and rich fish needs just salt and oil. A medical author would have similar criteria, though not the objectives of ornate phrasing and the height of pleasure.

Taste and texture (and links with habitat) are essential for the luxurious cooking of Archestratus (fragment 38):

Get the tail of a female tuna as well; I mean the big

She-tuna, whose mother-city is Byzantion.

Then cut it properly and roast it all,

After sprinkling it with fine-ground salt only and basting it with olive oil,

And eat the steaks hot, dipping them with pungent brine ... (trans. Olson \& Sens)

Note that the fish has a 'mother city', assimilating her to human culture rather than her own habitat; and the cut of fish is cooked with simple flavourings, nothing of the complex flavouring that Galen rejects (see below). As for cured fish, Archestratus is opinionated but accepts a light cure (fragment 39):

And a slice of Sicilian tuna $<>$

Cut when it was about to be pickled in jars.

But I say to hell with saperde, a Pontic dish,

And those who praise it. For few people

Know which food is wretched and which is excellent.

But get a mackerel (skombros) on the third day, before it goes into the salt water Within an amphora as a piece of recently cured, half-salted fish... (trans. Olson \& Sens, adapted)

This is luxurious cooking which does not depend entirely on large single fish, though that is much of the appeal. We will find a similar picture in the medical code of cooking 
also, large fish and small: both the turbot in Galen, and the goby in Hippocrates and Galen.

\section{Taste and Health}

On tasty food, Galen writes:

We physicians aim at benefits from foods, not at pleasure. But since the unpleasantness of some foods contributes largely to poor digestion, in this regard it is better that they are moderately pleasant in taste. But for cooks, a pleasant taste for the most part makes use of harmful seasonings, so that poor rather than good digestion accompanies them (Powell 2003). (On the Properties of Foodstuffs 2.51, trans. Powell, modified)

Taste is key, and it must be a pleasant taste. This is Platonic in thought but makes a major concession to pleasure-based words. If it is not pleasant to taste, a food will not be likely to be good for you.

Let us remember what constitutes good digestion is in the Hippocratic tradition of Galen: body heat breaks down foods that have moved from the gut into the bloodstream-in the liver principally. If the heat is excellent, all the nourishment will be converted into blood. If it is too great or too little, other humours will be formed, phlegm, yellow or black bile, which may accumulate in inappropriate parts of the body and produce 'residues', imbalances and ultimately disease. Unsuitable foods might also unbalance the body. For good health, good coction or digestion is paramount. The most nutritious foods according to Galen are wheat and pork, having the most energy. Some might be overwhelmed by such strong foods, especially if bread is poorly baked or pork cooked from a young animal that is too full of moisture. Fish can be excellent for health. To identify the best fish, taste will be the guide. Taste, for Galen, is one of the surest ways of identifying what the effect of a foodstuff might be on the body.

Take the case of the grey mullet:

When you eat it, the taste immediately indicates to you the better grey mullet. For its flesh is sharper, more pleasant and free from oiliness. The ones that are oily and watery are worse in the actual eating, but also worse concocted, bad for the stomach and of bad humour. (2.24)

Sharpness and pleasantness of taste are essential. They taste nice to the person eating, and ensure good digestion (cooking), good internal working in the stomach, and a good state of the bodily juices and flavours (humours). So too with rock-fish, noted already in the Hippocratic passage, pleasant taste and good blood go together. Galen identifies their habitat_rocks and headlands-and finds they are digested into ideal mean or average blood. The perfect food, medically speaking:

They term rock-fish those from the places in which they are found to dwell. For not in smooth or muddy or sandy beaches, but where there are rocks and headlands is the place they hide and reproduce. The best among them for pleasure is the parrot-wrasse (skaros)... Not only is the nourishment from them easy to digest, but it is very healthy for human bodies, generating blood of mean composition. I call 'mean' blood that which is not thin and watery, but also not excessively thick. (trans. Powell, modified) 
Among the rock fish Galen notes the goby, to which I have alluded already:

The fish is small and shore-frequenting, being itself one of the fish that always remain small. The one from sandy shores or rocky headlands is best for pleasure, for digestion, for distribution and for a healthy humoral state. But the one from river mouths, marshes and lagoons is not pleasant to the same extent, nor is it good in humours or easy to digest (Galen, On the Properties of Foodstuffs 3.27, trans. Powell, modified, 229.11-16 Wilkins)

Despite the reservations of D'Arcy Thompson, in Galen's estimation the goby produces good bodily fluids.

Galen's next category is soft-fleshed fish: it is an early medical category, but his comments are similar to Archestratus' on the sargue:

None of the soft-fleshed fish need vinegar, mustard or oregano, as the oily, sticky firm ones do. Nevertheless, some people use them by frying them, others by baking them or preparing them in a pan ... While the preparations from cooking pans are for the most part causes of a lack of digestion that with white sauce is best for it. (White sauce: water, olive oil, dill and leek boiled together)

Firm-fleshed fish are more of a challenge, as Archestratus noted. Galen recommends pickling. Again, texture is key.

Dogfish (galeoi) have flesh that is firm and full of residue, and so is cut up and pickled as food for ordinary people. In fact they are unpleasant and gelatinous, and therefore people eat them with mustard, and oil and vinegar, and with sharp dressings compounded of these. For tuna, especially the fresh ones, are unpleasant, but they improve when pickled ... Very young tuna after pickling are a match for the finest preserved fish. Most are imported from the Pontus and are only inferior to those from Sardinia and Spain. For indeed this preserved fish, with good reason, is highly valued for both tastiness and its soft flesh.

Again, taste and texture are key. Galen is not concerned with the economics of pickling, merely with the impact of pickled fish on the body. But this is part of his commentary on the diet as it was eaten.

When explicitly talking of pickled foods, pigs or fish, Galen has no objection to the finest versions. The codes are coming together once more.

The bodies of animals with flesh that is firm and full of residue are suitable for pickling... I mean by 'full of residue' fleshes that have interspersed within themselves a moisture that is rather full of phlegm... Pigs ... [Fish that are] fine in their substance, when taken as a meal, thin the thick, viscid humours. The finest that have come to my experience are the pickled fish from Cadiz.

We see the combining of the codes finally in the case of red mullet, a real gourmet food, but productive of the best blood at the same time:

This, too, is one of the pelagic fish and has been prized by men as superior to the rest in pleasantness of eating. It has flesh that is firmer than just about all of them and is quite friable. ... Therefore it is more nourishing when well digested than other fish. ... Red-mullet flesh is pleasant, being food proper to the nature of humans. (Galen, On the Properties of Foodstuffs 3.25-6, trans. Powell (modified) (225.24-227.10 Wilkins)) 
Some eaters of course go too far. Galen reproves such eating:

I enquired of one of those who were buying large red mullet at a high price whatever was the reason for his eagerness for them. He answered that while he bought old ones like those particularly because of the liver, he did so because of the head as well.

There are fascinating questions here. Galen's science and the luxury of Archestratus' cookery books are using the cooking of fish in closely similar ways. Galen's science has been shaped by the culture around him, as with all science. But the sentence I would note is that red mullet is a food 'proper to the nature of humans'. The fish, part of the wildness of nature as I set out at the beginning, can, by the processes of cooking and medicine, be made oikeios, part of the human world. Very close to the human body. It IS part of our world, whether or not it is part of the luxurious world as well when in short supply. The luxurious world can pursue the rare and exquisite, and can flex the muscles of its buying power without much regulation-Galen notes it. But it is a small part of the intersections of the worlds of human being and fish.

Open Access This article is distributed under the terms of the Creative Commons Attribution 4.0 International License (http://creativecommons.org/licenses/by/4.0/), which permits unrestricted use, distribution, and reproduction in any medium, provided you give appropriate credit to the original author(s) and the source, provide a link to the Creative Commons license, and indicate if changes were made.

\section{References}

Davidson J (1997) Courtesans and fishcakes. Harper Collins, London

Detienne M, Vernant J-P (1979) La Cuisine du sacrifice. Gallimard, Paris

Gallant T (1984) A Fisherman's tale. Miscellanea Graeca Fasc. 7, Belgian Archaeological Mission in Greece, Gent

Olson D, Sens A (2000) Archestratos of Gela. Oxford University Press, Oxford

Powell O (2003) Galen: on the properties of foodstuffs. Cambridge University Press, Cambridge

Purcell N (1995) The paradoxes of seafood. In: Wilkins J et al. (eds) Food in antiquity. University of Exeter Press, Exeter, pp 132-149

Thompson DW (1947) A glossary of Greek fishes. Oxford University Press, Oxford

Wilkins J, Hill S (2011) Archestratus: the life of luxury. Prospect Books, Totnes 